\title{
The upward tilt of honeycomb cells increases the carrying capacity of the comb and is not to prevent the outflow of honey
}

\author{
Robert OEDER ${ }^{1}$, Dietrich SCHWABE $^{2}$ \\ ${ }^{1}$ Lärchenstraße 16, Marktl D-84533, Germany \\ ${ }^{2}$ I. Physikalisches Institut, Justus-Liebig-Universität Giessen, Heinrich-Buff-Ring 16, Giessen D-35392, Germany
}

Received 14 March 2020 - Revised 11 July 2020 - Accepted 19 August 2020

\begin{abstract}
The cells of the combs of Apis mellifera are tilted upwards by approximately $13^{\circ}$. The literature says that this tilt serves to prevent the outflow of honey. We checked this by hanging empty honeycombs upside down into beehives. Honey was stored in these inverted honeycombs in the same way as in the normally oriented combs, and inverted combs were also well accepted for rearing the brood. We thus show that the benefit for the bees of the upward tilt of the cells is not to prevent leakage of honey. Honey is obviously in a Wenzel state on the hydrophobic, micro-structured cell walls. The associated wetting of the cell wall causes adhesion that prevents leakage. We propose that the benefit of the inclination of the cells is to direct about $10 \%$ of the weight of cell contents onto the midwall, thus increasing the carrying capacity of the comb.
\end{abstract}

honeycomb architecture / upward inclined cells / weight carrying capacity of the comb / leakage of honey / wetting of cell walls by honey

\section{INTRODUCTION}

The honeycomb is admired for long times for the appealing exactness of its hexagonal pattern of cells, for its light weight, for carrying a heavy weight of honey, and for the multipurpose use in storing honey and raising the brood in the same cell type. The hexagonal pattern is so attractive that even mathematicians and philosophers have spent contemplations on it. In the nineteenth century, the concept arose of not considering bees and honeycombs separately but of equating a bee colony with a single animal. In modern biology, the term superorganism is established as an expression that a bee colony is equivalent to a mammal

Corresponding author: D. Schwabe,

Dietrich.Schwabe@physik.uni-giessen.de

Manuscript editor: David Tarpy with its organs and characteristics (Tautz 2008). The complement of wax combs produced by the bees themselves is regarded as an integral constitutive component and a particularly important organ of this superorganism (Pratt 2004). The combs not only are living space, food store, and nursery but also serve the superorganism as the skeleton, sensory organ, nervous system, memory store, and immune system. Since a bee colony is only viable as an indivisible whole, it is essential to investigate the properties and function of its organs in order to comprehensively understand the biology of the superorganism. This applies in particular to the honeycombs with their manifold functions and their interdependencies with other colony organs. One of the properties of the honeycomb, which has received little attention so far, is the tilt of its cells by approximately $13^{\circ}$ upwards (Figure 1). This feature is only mentioned in very few scientific publications and without profound 


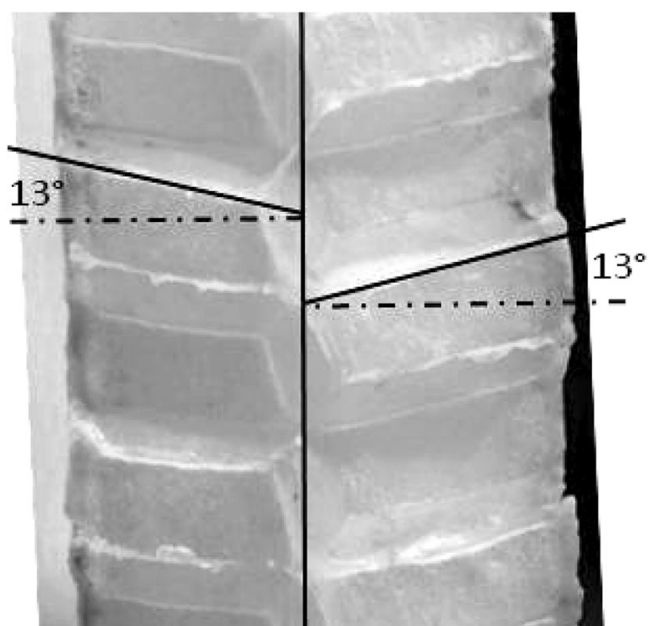

Figure 1. Photograph of a vertical cut through a comb perpendicular to the midwall displaying the upward tilt of the cells by $13^{\circ}$. The lines were drawn and the angles determined by using MS PowerPoint as described in Section 2.3.

considerations. Earlier in history, scientists have already assumed that the general structure of combs is one of the reasons for the strength of the construction. For Maraldi (1712), the benefit of the pyramidal shape of the bottom and the interlacing of the cells is that the three prismatic walls meeting in one edge serve as support for the bottom of an opposing cell. Also Vogt (1911) sees an explanation for the shape of the comb cell in the achieved strength of the building. Hüsing and Nitschmann (1987) describe in their encyclopedia en passant and without explanation the inclination of the cells as the basis for the stability and carrying capacity of the comb. For Oeder and Schwabe $(2017 \mathrm{a}, \mathrm{b})$ the tilt of the cells was an argument against the hypothesis that bees first build cylinders which are then transformed into hexagonal cells (Pirk et al. 2004). There is also a widespread but unproven opinion in the literature which could be regarded as a "historical truth" that the inclination of the cells is to prevent the honey from leaking (Frisch 1959; Hüsing and Nitschmann 1987; Dietemann et al. 2011; Tautz 2012; Gallo and Chittka 2018; Wahyudi 2018). This explanation seems to be so convincing and obvious that until today, scientists have not found it worthwhile to test its validity experimentally.
There is only one exception by Müllenhoff (1883), who states that the inclination of the cells is very important for the bees: "Combs which are glued inverted in a frame by the beekeeper will not be used by the workers for storage of honey and the queen will not use them for laying eggs. Such combs remain disregarded in the hive or are broken off." This is the only work indicating an experimental check of the "honey outflow hypothesis". However, there is no description by Müllenhoff of the applied experimental setup. We tested Müllenhoff's statements by providing the bees with inverted combs in supers for honey and in the brood chamber of a beehive.

With our investigations, we wanted to find out whether the above convictions and statements can be confirmed experimentally. A thorough understanding of the interaction of hydrophilic liquids with hydrophobic solid surfaces is essential for this. This topic is dealt comprehensively in the more recent literature in the general context of wetting surfaces. New physico-chemical studies describe a previously unknown wetting behavior of water and honey on beeswax (Guo et al. 2015), which is of great interest for the present work. Taking this into account in the discussion of our results, we came to new insights about the leakage of honey, which in turn led us to a new interpretation of the inclination of the comb cells and its benefit for the bees.

\section{MATERIAL AND METHODS}

\subsection{Location and environment of the beehives}

We started the tests in mid-April 2018 with a total of six bee colonies (Apis mellifera carnica) in order to find out how the inclination of the cells affects the honey input. Two colonies had their locations in southeastern of Bavaria (463 m and $370 \mathrm{~m}$ above sea level) and four about $400 \mathrm{~km}$ away in Upper Hesse (198 m above sea level). One of the colonies in Bavaria was located in a residential area and one in an agricultural area. The location in Hesse was in a settlement with an agricultural area about $300 \mathrm{~m}$ away from it. There are fruit trees at all sites, and we assume that the nectar collected during this time is mainly from 
these trees (peach, cherry, apple, and plum). There was plenty of nectar for the bees to collect during the test period from mid-April to early May 2018.

\subsection{Preparation of inverted honeycombs}

For our experiments, we used extracted and dry honeycombs with foundation from the previous year with 5.2-mm cell size. Immediately after extraction, these combs have been given back into beehives for about $48 \mathrm{~h}$ to be thoroughly cleaned and prepared by the bees. Frames were used with the measure 2/3 Langstroth and 1/2 German Normal.

The ears at the top bars of the test frames were cut off to allow inverted frames to fit into the supers. At the bottom bars, nails were hammered in so deep that the protruding iron pins could serve as a support for the honeycombs in the super for honey. The frames with honeycombs prepared in this way were hung with the top bars down into the middle of the supers for honey of the test colonies. The cells of these honeycombs were now tilted downwards. The cells of the honeycombs to the right and to the left of it were tilted upwards. The super for honey and super for the brood were separated by a queen excluder in all cases.

The beehives were commercially available closed boxes, which were dark inside. The honeycombs were removed for some minutes from the beehives in daylight, weighed, and then immediately put back into the dark hive. The test honeycombs were weighed every few days with digital kitchen scales $( \pm 1 \mathrm{~g})$, and the weights were compared with those of the neighboring honeycombs with normal cell orientation.

\subsection{Measurement of the inclination angle}

All cells of the normally oriented honeycombs, with the exception of those directly attached to the top bar, were inclined upward by $13^{\circ}$ with respect to the horizontal. Since it was irrelevant for our experiments to know the exact angle, we only roughly measured this angle in two ways. We placed a frame with a naturally built comb vertically on a table and looked horizontally into the cells against a bright background. In this position, the tip of the rhombic cell bottom appears close to the lower tip of the hexagonal cross section of the cell. Then, we tilted the frame towards the viewer until the tip of the cell bottom was shifted to the middle of the cell. On a protractor, we could read that the frame was tilted by about $13^{\circ}$.

A second way to measure the tilt angle was to take a photo of a vertical cut through a natural comb and to insert the photo into MS PowerPoint. We marked the midwall with a straight line. We rotated two other lines, which were initially parallel to the midwall line, with the rotate option of MS PowerPoint until they coincided with the edges of opposite cells (Figure 1). The rotation angles were $77^{\circ}$ and $103^{\circ}$ corresponding to a tilt angle of the cells of $13^{\circ}$ on both sides of the comb. We therefore have used this tilt angle of $13^{\circ}$, which is consistent with the literature (Martin and Lindauer 1966), for our further considerations.

\subsection{Test with a water droplet to observe the wetting in the cell}

We also carried out experiments to simulate the filling of cells with honey at an early stage. Single drops of water do not fill the whole cross section of a cell. If a drop is held in the cell when the opening is turned down, this would show that the drop sticks to the hydrophobic cell wall only by adhesion forces.

We prepared a column of cells from a honeycomb with vertical cuts. We held the cells with the opening vertically upwards and pipetted single drops of water into them. The drops fell into the cells approximately to the connecting line between the cell wall and cell bottom. Then, we turned the opening of the cells down and repeated the experiment about 10 times always with another cell. The drops had a volume of approx. $60 \mu \mathrm{l}$, which corresponds approximately to the honey stomach capacity of the bee. We were able to observe the behavior of the drops in the cell despite the low contrast in the back light.

\subsection{Preparing frames to get bees build combs bottom up}

In order to answer the question whether the inclination of the cells depends on the direction in which the bees build the comb, we wanted the 
bees to build a honeycomb from the bottom up. We have prepared a frame without a top bar, as shown in Figure 4, and hung it in the middle of the super for honey. We covered the frames with a thin plastic foil, as it is widely used by beekeepers. As hoped, the bees did not start building a honeycomb from top to bottom on this foil, but built a honeycomb from bottom up on the bottom bar of the open-top frame. Since we had positive results from preliminary experiments, we confined ourselves to a single experiment under controlled conditions.

\subsection{Offering the bees an inverted comb for breeding}

In order to find out whether the bees accept inverted combs for rearing the brood, we extracted the honey from an inverted honeycomb. We hung the extracted comb into a brood chamber of a hive consisting of 2/3 Langstroth bodies so that it was positioned in the middle between the normal combs. The bees immediately occupied the inverted comb after it was inserted into the hive. The integration of the inverted comb into the brood nest already after 1 day was supported by the fact that there was a brood on the neighboring combs. For the experiment, we used two inverted combs in different colonies.

\section{RESULTS}

\subsection{Storing of honey in inverted honeycombs}

The aim of our experiments was to observe whether the bees store honey in the inverted honeycombs and, if so, what happens to the honey. If the tilt of the cells is to prevent the leakage of honey, then the honey should leak out of cells tilted downward or not even be brought in by the bees.

To our surprise, the bees stored honey in the inverted honeycombs in very much the same way as in the neighboring normally oriented honeycombs. After 17 to 23 days, the inverted honeycombs were full and capped (Figure 2). No leakage of honey could be detected at the inverted honeycombs at any time.
The initial weight on day zero on the $x$-axis is not the same for the three honeycombs, since at the start of the experiments, honey was already stored in the combs next to the inverted comb. The differences in initial weight did not affect our results because we did not care about the absolute weight of the combs, but about the weight increase. Differences between the honeycombs in a hive are expected when the bees take different and changing paths through the brood chambers to come to the honeycombs. The differences in weight increase from hive to hive should mainly be due to different colony strength and different weather conditions that influence foraging. The important point is that the weight increase was roughly parallel in time for the inverted compared with the neighboring normally oriented combs. There is no indication that normally oriented cells are preferred for honey storage by the bees above inverted ones.

Concerning the capping (e.g., doming of the covers), we could not detect any difference between the inverted and the adjacent honeycombs by visual inspection (Figure 3 ).

\subsection{Behavior of single drops of water in a cell}

We wanted to get an idea of the behavior of the first honey drops deposited by the bees in a cell. For that purpose, we applied single drops of water, each with a volume of about $60 \mu \mathrm{l}$, with a pipette into a cell. This drop size corresponds approximately to the honey stomach capacity of the honeybee. No capillary forces could become effective in this experiment because the drops did not completely fill the cross section of the cell. But, the drops remained at their original place in the honeycomb cell, even though the opening of the cell was turned down.

\subsection{Combs built from bottom up}

If you give the bees a frame that has only a bottom bar and is otherwise open at the top or covered at the top by a thin plastic foil to which the bees do not attach a comb, then the bees could start to build a comb from the bottom up under very good foraging conditions. The bees actually 

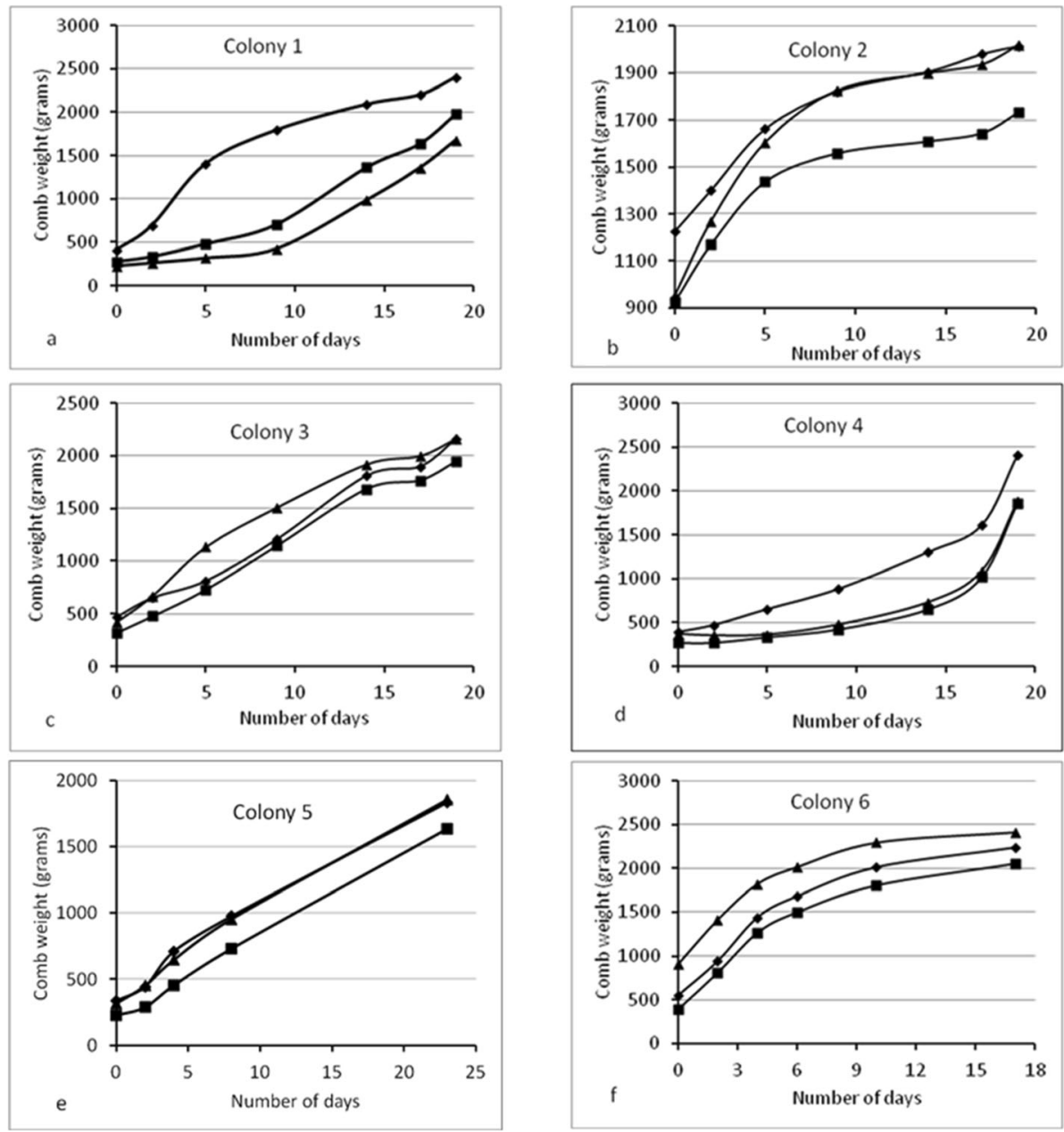

Figure 2. Weight increase of three honeycombs examined in each of the six beehives. Zero on the $x$-axis indicates the start of weighing, followed by further weighings after the respective number of days. The lines for the honeycomb weights in the graphics are marked with the following symbols: comb 4 on the left side of the inverted comb as looked from the back side of the beehive, $\boldsymbol{\|}$ inverted comb, $\boldsymbol{\Delta}$ comb 6 on the right side. The inverted comb was positioned between comb 4 and comb 6. Colonies 1-4 (a-d) were located in Hesse, colonies 5 and $6(\mathbf{e}, \mathbf{f})$ in Bavaria.

built a comb from the bottom up, and our expectation was that the cells then are inclined downward from the midwall to the opening of the cells. But even in this case, we observe the same inclination of the cells upwards (Figures 4 and 5).

\subsection{Rearing the brood in inverted combs}

After extracting the honey from the comb and after cleaning by the bees, an inverted honeycomb was hung into the brood chamber of a colony kept in a hive consisting of $2 / 3$ Langstroth hive bodies for both the brood and honey. The queen has immediately created breeding areas with only few gaps (Figure 6) on both sides of the inverted honeycomb. The inverted honeycomb was incubated several times.

This refutes the claim of Müllenhoff (1883) that honey bees do not accept inverted combs for the rearing of the brood. Due to the lack of a 

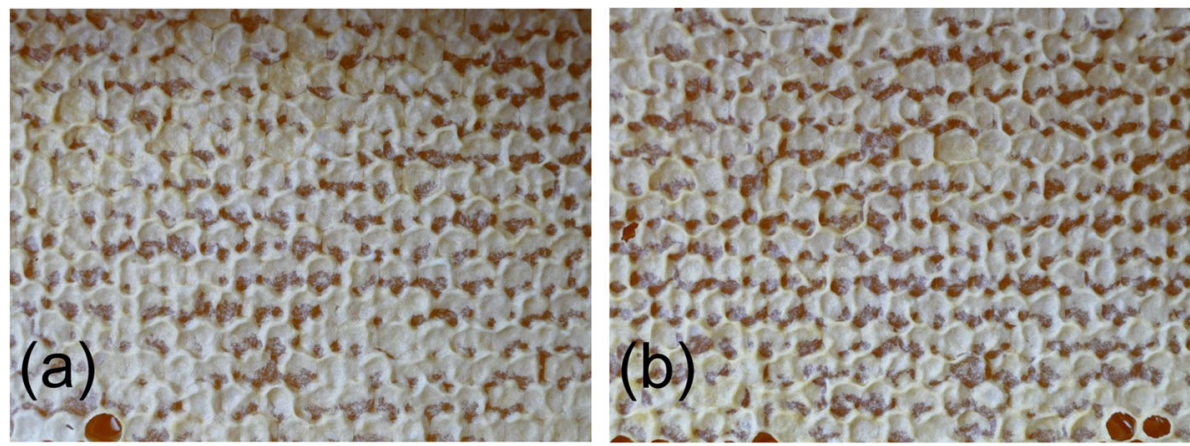

Figure 3. We observe no differences in the overall capping and in the shape of the individual caps of the normally oriented comb (a) and the inverted comb (b). A few larger cells (presumably drone cells) near the lower rim of the photographs appear dark and are not capped because they are not yet completely filled with honey.

description of these older experiments, we unfortunately cannot retrace the possible reasons that led to his contrary results.

\section{DISCUSSION}

\subsection{Adhesion of honey on the cell walls prohibits outflow}

The question is which mechanisms prevent honey from leaking out of the downward inclined cells, although beeswax is hydrophobic.

The wetting behavior, i.e., the way in which liquids behave on the surface of solids, depends on the surface tension of the liquid, the solidliquid interfacial tension, and the free surface energy of the solid. The contact angle of a drop of liquid on a solid surface (Figure 7a) depends on these thermodynamic variables. It is therefore a direct measure of the wettability of an ideal specific surface by a certain liquid. Wetting liquids form a contact angle $\Theta$ of less than $90^{\circ}$, nonwetting ones of more than $90^{\circ}$. But, also the surface chemistry and the surface topography on a micro- and nano-scale have a major influence on the wetting of real surfaces. They are decisive for whether a drop of liquid on a surface is in the Wenzel state or in the Cassie-Baxter state. According to the Wenzel model, the roughness increases the total area of a solid surface, which also geometrically modifies the wetting properties of this surface (Wenzel 1949). In the idealized Wenzel regime (Figure 7a), the liquid penetrates into all grooves in the surface structure and completely covers the rough surface without air pockets. In the Wenzel state, drops adhere strongly to the surface, so that the ability of the surface to repel a liquid is greatly reduced or completely lost. In the Wenzel state, the motion of a drop on such a surface can be hindered although the contact angle is larger than $90^{\circ}$. Inspired by biological attachment systems, Cheng et al. (2010) reported on polystyrene surfaces that show both contact angles larger than $150^{\circ}$ and high adhesion of water. With increasing roughness, the system changes from the Wenzel regime to the Cassie-Baxter
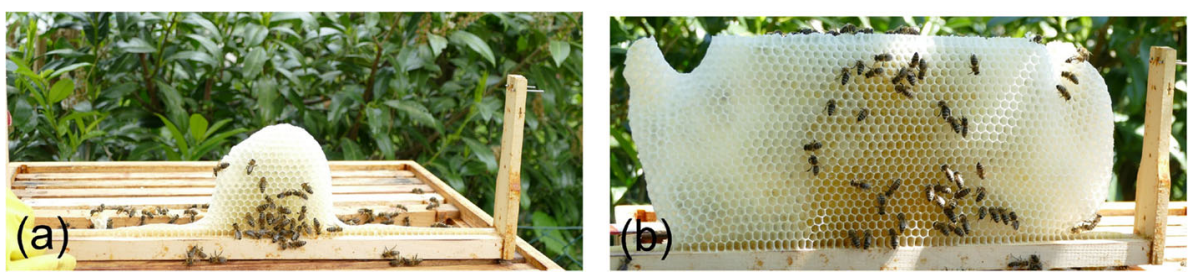

Figure 4. Honeycomb built from bottom to top in a frame without a top bar. a Initial state. b Honeycomb with final size. 
regime, i.e., the proportion of air in the interface increases significantly. A heterogeneously wetting drop (Figure 7b) lies only upon the asperities of the surface structure. Thus, the hydrophobicity of the surface is strengthened because the drop sits partially on air pockets that are bounded between the surface and liquid (Stenzel and Rehfeld 2013).

Guo et al. (2015) investigated the wettability and the adhesion behavior of the natural cell wall of a honeycomb for water and for honey droplets. On high-magnification ESEM images, they detected nano-scale protuberances on the surface of

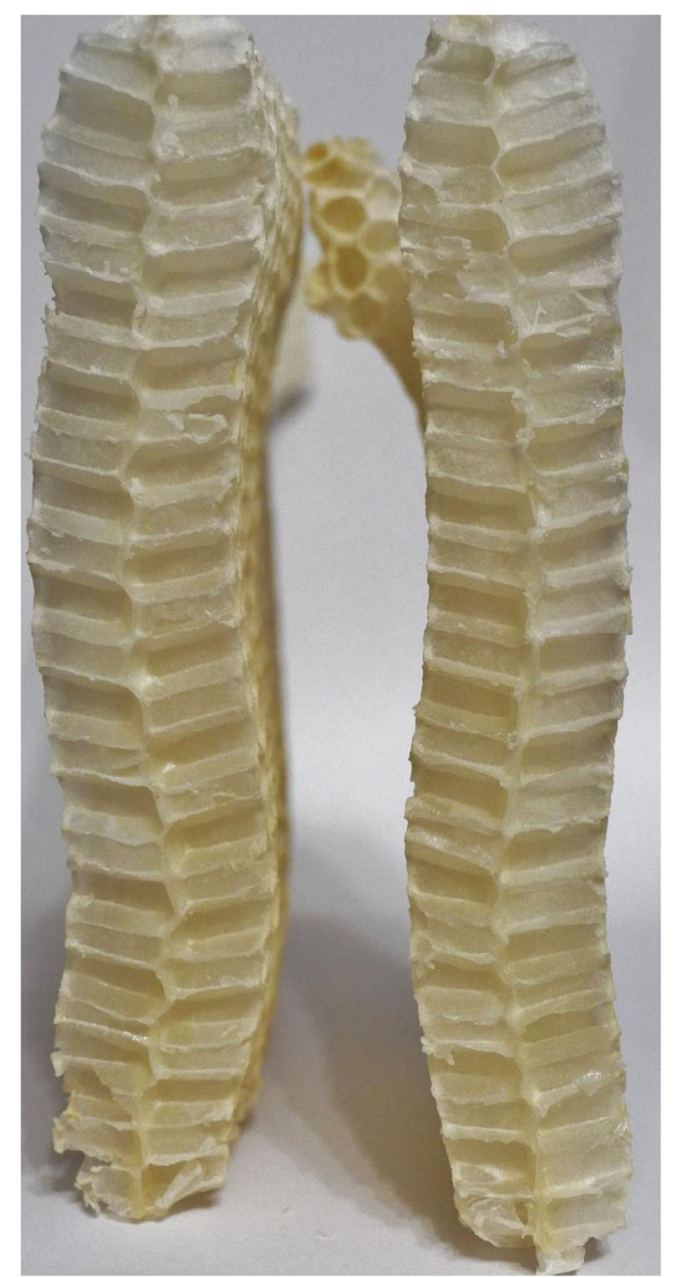

Figure 5. Honeycomb, which was built from the bottom up, cut apart and both parts put against each other. The inclination of the cells is also upwards as in a honeycomb built from top to bottom. cell walls and micro-scale wrinkles of 200-500 $\mathrm{nm}$ and $0.5-2 \mu \mathrm{m}$, respectively. Similar structures are shown in the photographs of Espolov et al. (2014). Guo et al. (2015) experimented with water and honey droplets with a volume of $10 \mu \mathrm{l}$. For the contact angle of water, they measured $\alpha=$ $108.4+5.81^{\circ}$, for honey $\alpha=130.6+1.51^{\circ}$. The natural honeycomb cell wall is therefore hydrophobic for both water and honey $\left(\alpha>90^{\circ}\right)$. However, they found that both water and honey drops stick to the surface, even if the cell wall is turned $180^{\circ}$ with the drops hanging downward.

The adhesive property of the hydrophobic cell walls is due to their surface topography on the micro- and nano-scale. The roughness is just such that water and honey penetrate into the grooves of the surface structure and completely wet the surface of the cell wall without air entrapment (Schäfle 2002). The contact state of a drop of water or honey on the textured cell wall is therefore always a Wenzel state with a high adhesion between the drops and the cell wall.

The maximum adhesion forces for the water and honey droplets are $201.6 \mu \mathrm{N}$ and $157.8 \mu \mathrm{N}$, respectively (Guo et al. 2015). This more than compensates the weight of $100 \mu \mathrm{N}$ of a drop of water or 140 $\mu \mathrm{N}$ of a honey droplet of $10-\mu$ l volume.

Whether a Wenzel state exists also depends on the surface chemistry (Stenzel and Rehfeld 2013). Beeswax consists of $12 \%$ free acids and $1 \%$ free alcohols (Tulloch 1980), which influence the mechanical properties and structural characteristics of beeswax (Buchwald et al. 2009). Free fatty acids and alcohols (Callow 1963) could form hydrogen bonds to water and honey by their carboxyl or hydroxyl groups, thus contributing to their adhesion to the cell surface. It can be assumed that these polar groups are oriented towards the surface in the non-polar matrix.

In our case, three main factors are effective in holding the honey in the cell: the adhesive forces between the honey and the cell wall, the small diameter of the cell, and the surface tension of the honey. The capillary forces resulting from the combination of these factors prevent the honey from flowing out because this would create a negative pressure on the cell bottom. This indicates that capillary pressure helps to hold the honey in the cell against gravitational forces. 


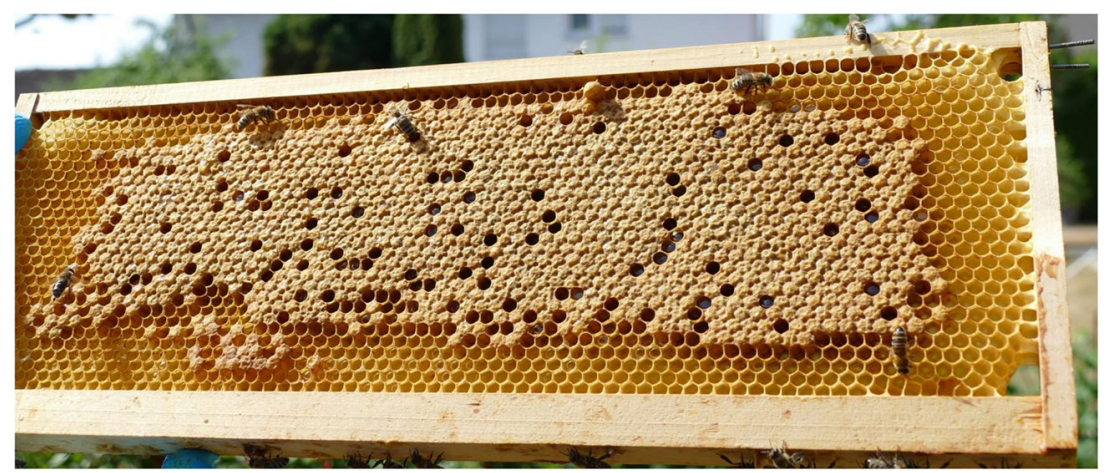

Figure 6. Brood area on a comb with cells tilted downwards.

In our experiment with water drops which we pipetted into cells, we observed that the drops remained at their original place in the honeycomb cell, even though the opening of the cell was turned down. This behavior of the drops is facilitated by the fact that the drop placed in the $120^{\circ}$ corner of the honeycomb cell has a contact surface about twice as large as the one placed on a flat cell wall as investigated by Guo et al. (2015). The contact surface is even larger, and thus also the adhesion force, when bees deposit honey droplets in the tip of the bottom, which consists of three rhombuses.

At this point, we want to mention two interesting aspects related to harvesting of honey. Before extracting the honey, beekeepers can check the ripeness of the honey in uncapped cells by using the "shake test". When the honey is ripe, its surface tension is so high that, despite the vigorous downward shaking of the horizontally held honeycomb, no honey drips out.

Later, after the extraction of the honey, some residual honey sticks to the cell surfaces despite the high centrifugal forces during the extraction process. Here, the adhesion to the cell walls has prevented the honey from being extracted completely out of the honeycombs.

\subsection{Orientation of cells in honeycombs built under special conditions}

The inclination of all cells, which are not directly near the ceiling, is always observed in the combs of Apis mellifera. We therefore assume that the upward inclination has a meaning. We showed that the purpose is not to prevent the leakage of honey and that it is also not a requirement for rearing the brood. Then, what is the point?

When bees build honeycombs from top to bottom, the cells are inclined upwards against the direction in which the comb building is progressing. Therefore, our initial guess was that the inclination of the cells against the direction of construction could be a general principle of comb building. Accordingly, the cells should be inclined downward
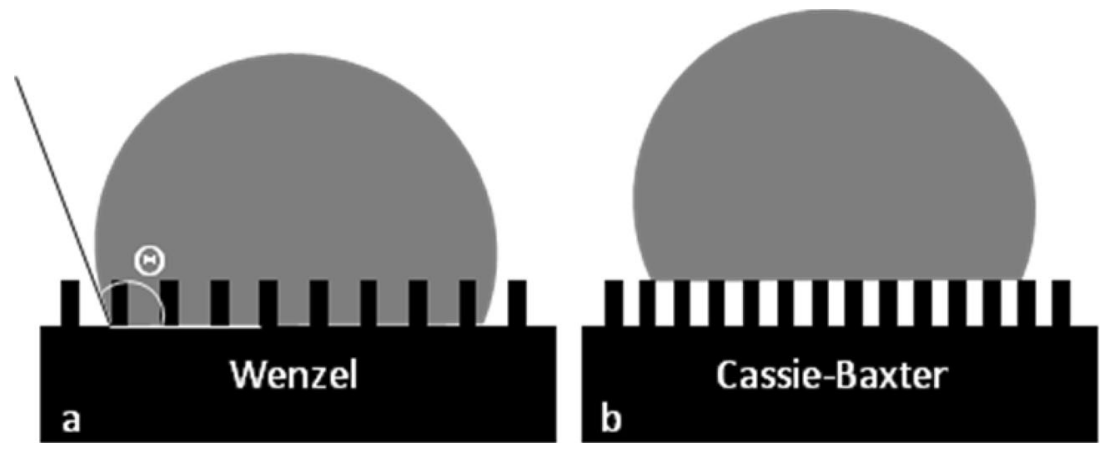

Figure 7. Models for wetting. a Wenzel. b Cassie-Baxter, contact angle $\Theta$. In the Wenzel state, drops are adhering strongly to the surface. 
when the honeycomb is built from the bottom up. But in our experiment, in which we made the bees to build a comb from the bottom up, we found that also in this case, the inclination of the cells was upward as if the comb had been built from top to bottom (Figures 4 and 5). If we ask which parameter remains the same when building from top to bottom and vice versa, it is the direction of gravitation. This indicates that the inclination of the cells does not depend on the direction of construction, but obviously on the direction of gravity. This is consistent with Martin and Lindauer (1966) who found that the bees use the neck organ in the comb-building process to control the orientation of the comb components in the gravity field.

When using foundations, it can be observed that the bees start drawing out many cells at the same time on larger and distant areas. We suppose that bees drawing out cells on the foundation at some distance from each other do not exchange information about the cell construction. In the end, however, all cells are tilted upwards in the same way. All bees seem to have the same plan, namely to build upward-tilted cells. If foundations are used, there is no defined direction of the building from top to bottom or vice versa as is the case with natural combs. Again, it is reasonable to assume that gravity is the determining factor for the common alignment of the tilt of the cells.

During a Space Shuttle mission, bees constructed combs with cells of normal dimensions under reduced gravity conditions (around $10^{-4} \mathrm{~g}$ in various but unknown directions, with $g=$ normal gravity). However, compared with combs built on the Earth, the comb cells were not consistently inclined "up/ down" (in one direction). This is not surprising, since in weightlessness, no obvious "downward movement" occurs for a honeybee (Vandenberg et al. 1985). During the STS-41C mission of Spacelab, bees produced several pieces of honeycomb. For two of the orbiter comb pieces, cells were angled in the same direction on any one side. For the larger piece, cells on one side were angled up towards the Lexan top, while on the other side, the cells were angled down towards the Bee Enclosure Module (BEM) floor. The "up-angled" cells had a higher average angle than the "down-angled." The terms "up" and "down" in microgravity are only meaningful in relation to the BEM. Another piece, which apparently started from the BEM floor, displayed a wide range of angles (Poskevich 1984). Here, too, it can be seen that the inclination of the cells is an intrinsic phenomenon in comb construction, but the inclination of the cells is not well defined under microgravity. However, the inclination of the cells occurs under all external circumstances, and it becomes evident that gravity on Earth is crucial for the known orientation of the angle of inclination of comb cells.

\subsection{The tilt of the cells upwards increases the load capacity of the comb}

Since the direction of inclination of the cells is controlled by gravity, it is obvious to assume that the inclination has something to do with the effect of gravity. Our hypothesis is therefore that it could increase the load capacity of the comb as lined out in Figures 8 and 9.

In Figure 8, we show the decomposition of the gravitational force $F_{g}$ into the components $F_{w}$ parallel and $F_{p}$ perpendicular to the cell wall. We see that due to the inclination by $13^{\circ}$, a component $F_{w}$ of the weight $F_{g}$ of each cell (filled with honey) is directed towards the midwall.

The midwall is the only structural element of a comb which is aligned in the direction of gravity $g$ and which can therefore carry gravitational forces best. The midwall is also thicker than the cell walls. The component $F_{w}$ could give rise to bending of the midwall, e.g., if the cells on both sides of the midwall are not evenly long or not evenly filled. However, if this symmetry is given, the force exerted by the component $F_{w}$ on one side is compensated by the corresponding force on the opposite side (Figure 8). With the force $F_{g}=$ $m * g$ with honey mass $m$, acceleration of gravity $g$, and the upward inclination angle $\alpha$, we find $F_{w}=m * g * \sin \alpha$ and with $\alpha=13^{\circ}, F_{w} / F_{g}=$ $\sin \alpha=0.225$. At an inclination angle of $13^{\circ}$, a fraction of $22 \%$ of the total weight $F_{g}$ is directed towards the midwall in this approach.

The larger component $F_{T}$ of $F_{g}$ exerts a torque $T=D / 2 * m * g * \cos \alpha$ on the cell ensemble, where $D$ is the depth of the cells. The torque is also reduced by the inclination of the cells.

With respect to the forces $F_{w}$ acting on both sides of the midwall, we can construct a second 


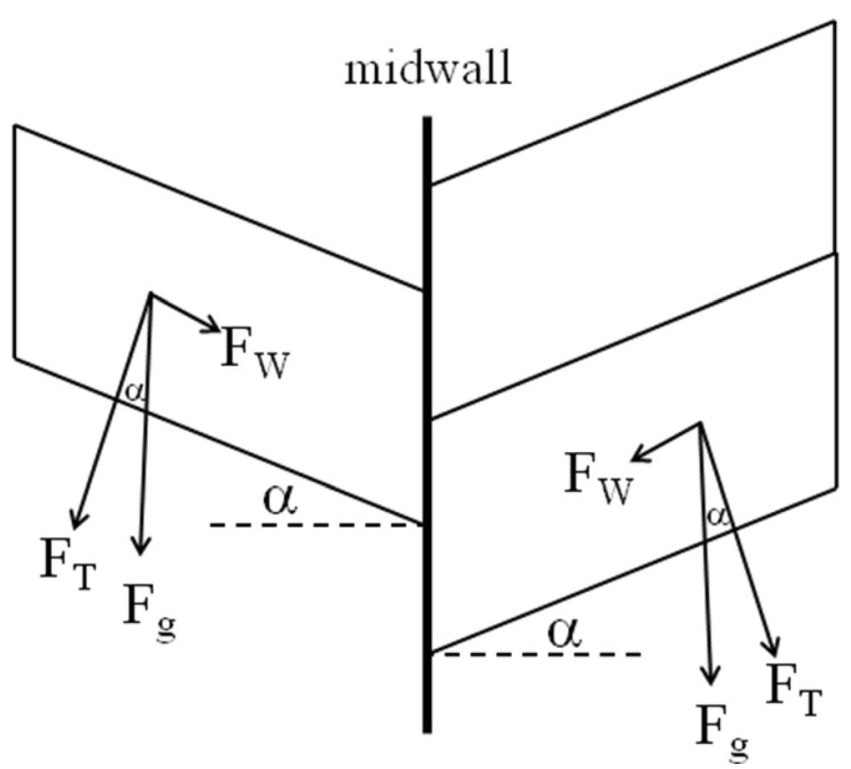

Figure 8. Schematic vertical cut through honeycomb cells with a tilt upwards by an angle $\alpha$ at both sides of the midwall, visualizing the upward tilt of the cells and the weight components $F_{w}$ and $F_{T}$ parallel and perpendicular to the cell wall.

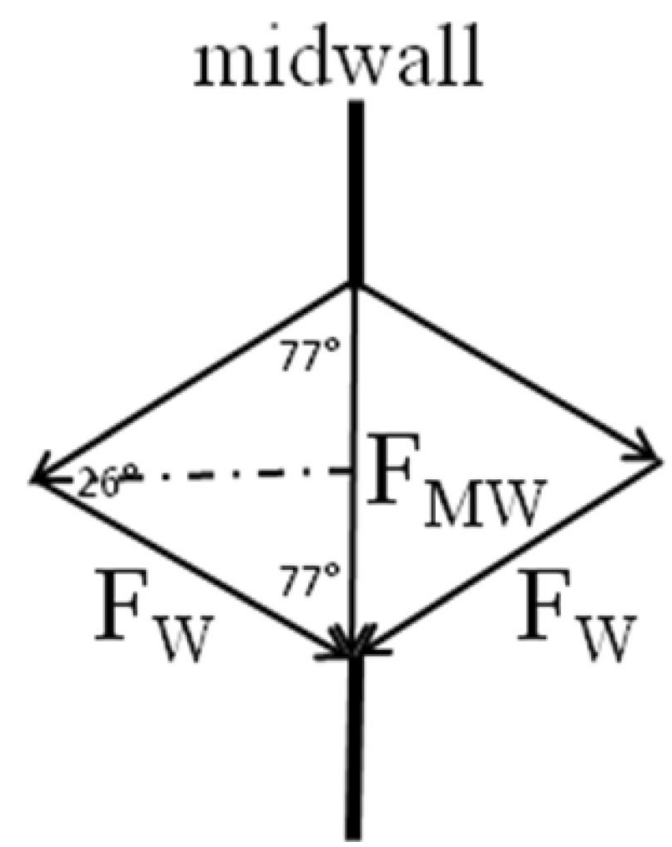

Figure 9. Parallelogram of forces $F_{w}$ taken from Figure 8 acting on the midwall (the upper lines are auxiliary lines to complete the parallelogram). The resulting force $F_{\mathrm{MW}}$ is directed downwards along the midwall. From this, it can be derived that as a result of the upward inclination of the cells, $10 \%$ of the load in the cells is transferred to the thicker midwall. parallelogram of forces from which we derive the resultant force $F_{\mathrm{MW}}$ in the direction of gravity, which is transferred to the midwall (Figure 9). With $1 / 2 * F_{\mathrm{MW}} / F_{w}=\sin \alpha$ and $F_{w}=F_{g} *$ $\sin \alpha$, we get $F_{\text {MW }}=0.1 * F_{g}$. As a result of the inclination of the cells, $10 \%$ of the load in the cells is absorbed by the midwall.

The importance of a high load-carrying capacity of the comb for the bees becomes evident when one considers that the height in natural nesting holes can exceed $3 \mathrm{~m}$ and the nest inside the cavity typically possesses the same shape and size (Seeley and Morse 1976).

In summary, we note that the purpose of the upward tilt of the honeycomb cells is not to prevent the leakage of honey. It is also not a prerequisite for rearing the brood. We think that the main benefit of the tilt of the cells is to direct a significant part of gravitational forces of the cell content onto the midwall and thus to increase the total carrying capacity of the honeycomb. Since a larger tilt angle would reduce the height of the cell and thus the cell volume and the space for the brood, the inclination angle must be limited. The bees have chosen for the tilt a value of about $13^{\circ}$. In this respect, the bees take into account the size and body shape of worker and drone pupas, 
but they do not use their own bodies as a mold in the comb-building process (Oeder and Schwabe 2017a, b).

Honeybees build combs with minimal wax consumption and maximum strength and capacity. The multipurpose use of the combs comprises raising the brood, storing the stocks, and the communication of the bees through their vibration characteristics. The inclination angle of about $13^{\circ}$ upwards seems to be the best compromise for the bees between increasing the carrying strength of the honeycomb and the provision of a cell volume adapted to the requirement of the brood.

\section{ACKNOWLEDGEMENTS}

We thank the Justus-Liebig-University Gießen that we could take advantage of its infrastructure services.

\section{AUTHOR'S CONTRIBUTIONS}

R. Oeder had the idea for the experimental test. He contributed most of the figures. Experiments, evaluation, interpretation and writing was by approximately $50 \%$ from both authors

\section{FUNDING}

Open Access funding provided by Projekt DEAL.

\begin{abstract}
L'inclinaison vers le haut des alvéoles est destinée à augmenter la force portative du rayon et n'à empêcher pas une fuite de miel
\end{abstract}

architecture des rayons de miel / inclinaison des cellules vers le haut / capacité de charge du rayon / écoulement de miel / mouillage des parois cellulaires par le miel

Die Aufwärtsneigung der Zellen soll die Tragfähigkeit der Wabe erhöhen und nicht das Ausfließen von Honig verhindern

Wabenarchitektur / Neigung der Zellen nach oben / Tragfähigkeit der Wabe / Abfluss des Honigs / Benetzung der Zellwände durch Honig

\section{REFERENCES}

Buchwald, R., Breed M.D., Bjostad L., Hibbard B.E. (2009) The role of fatty acids in the mechanical properties of beeswax. Apidologie 40, 585-594

Callow R.K. (1963) Chemical and Biochemical Problems of Beeswax, Bee World $44: 3$, 95-101

Cheng Z., Gao J., Jinag L. (2010) Tip geometry controls adhesive states of superhydrophobic surfaces, Langmuir 26 (11), pp 8233-8238

Dietemann, V., Duvoisin, N., Lehnherr, B. (2011) Das schweizerische Bienenbuch, Band 2, Biologie der Honigbiene. Druckerei Appenzeller Volksfreund

Espolov T., Ukibayev J., Myrzakozha D., Perez-Lopez P., Ermolaev Y. (2014) Physical and Chemical Properties and Crystal Structure Transformation of Beeswax during Heat Treatment. Natural Science 6, 871-877

Frisch V. K. (1959) Aus dem Leben der Bienen. SpringerVerlag Berlin, p. 9

Gallo V., Chittka L (2018) Cognitive Aspects of CombBuilding in the Honeybee? Front. Psychol. 9, Article 900, doi: https://doi.org/10.3389/fpsyg.2018.00900

Guo T., Li M., Heng L., Jiang L. (2015) Special adhesion of natural honeycomb walls and their application. Phys.Chem.Chem.Phys. 17, 6242 DOI: https://doi. org/10.1039/c4cp04615c

Hüsing J. O., Nitschmann J. (1987) Lexikon der Bienenkunde, Edition Leipzig und Ehrenwirt Verlag, p. 366

Maraldi G. F. (1712) Observations sur les abeilles. Memoires de l'acad. p. 391-438.

Martin H., Lindauer M. (1966) Sinnesphysiologische Leistungen beim Wabenbau der Honigbiene. Z. Vergl. Physiol. $53: 372-404$

Müllenhoff K. (1883) Über die Entstehung der Bienenzellen. Berliner Entomolog. Zeitschrift 27 (1): 167

Oeder, R., Schwabe, D. (2017a) Honigbienen (Apis Mellifera) bauen die rhombische Mittelwand und die hexagonalen Zellen ihrer Waben direkt und ohne Zwischenstrukturen. Oberhess. Naturwiss. Zeitschr. 67: 8-27, Giessen ISSN 0340-4498

Oeder, R., Schwabe, D. (2017b) Evidence that no liquid equilibrium process is involved in the comb building of honey bees (Apis Mellifera). http://geb.uni-giessen. de/geb/volltexte/2017/13152/pdf/ONZ_67_2017_ S08_6.pdf 2

Pirk, C.W.W., Hepburn, H.R., Radloff, S.E., Tautz, J. (2004) Honeybee combs: construction through a liquid equilibrium process? Naturwissenschaften $91: 350$ 353

Poskevich D. M. (1984) A Comparison of Honeycomb Structures Built by Apis mellifera (SE82-17). .jsc.nasa.gov/Experiment/exper https://sda/914 
Pratt S. C. (2004) Collective control of the timing and type of comb construction by honey bees (Apis mellifera). Apidologie 35 :193-205

Schäfle C. (2002) Morphologie, Verdampfung und Kondensation von Flüssigkeiten auf benetzungsstrukturierten Oberflächen. Dissertation, University of Konstanz

Seeley, T. D., Morse, R.A. (1976) The nest of the honey bee (Apis mellifera L.), Insects Sociaux 23 /4: 495-512

Stenzel V., Rehfeld N. (2013) Funktionelle Beschichtungen. Vincentz Network, Hannover, pp. 17-22

Tautz J. (2008) The Buzz about Bees-Biology of a Superorganism, Springer-Verlag Berlin Heidelberg

Tautz, J. (2012) Phänomen Honigbiene. S. 176, Springer Verlag Berlin Heidelberg

Tulloch, A. P. (1980) Beeswax-composition and analysis. Bee World 61, 2, 47-62
Vandenberg J.D., Massie D.R., Shimanuki H., Peterson J.R., Poskevich D.M. (1985) Survival, behavior and comb construction by honey bees, Apis Mellifera, in zero gravity aboard as NASA shuttle mission STS 13 . Apidologie 16(4):369-384

Vogt H. (1911) Geometrie und Ökonomie der Bienenzelle. Trewend und Granier, Breslau, Germany

Wahyudi I. W. (2018) Structure and production of honey bees maintained in traditional and modern nests in Tenganan village, Karangasem district. Proceeding Book - International Seminar Bali Hinduism, ISBN: 978-602-52255-0-5

Wenzel R. N. (1949) Surface Roughness and Contact Angle. J. Phys. Chem. 53 (9):1466-1467

Publisher's note Springer Nature remains neutral with regard to jurisdictional claims in published maps and institutional affiliations. 